TP Periodica Polytechnica Mechanical Engineering

\author{
61(3), pp. 153-160, 2017 \\ https://doi.org/10.3311/PPme.9013 \\ Creative Commons Attribution (i)
}

RESEARCH ARTICLE

\section{Analysis of Transverse Vibration Acceleration of a High-Speed Elevator with Random Parameters under Random Excitation}

\author{
Qing Zhang ${ }^{1,2^{*}}$, Yuhu Yang ${ }^{1}$
}

Received 13 January 2016; accepted after revision 03 January 2017

\begin{abstract}
The randomness of a high-speed elevator car system's parameters was caused by manufacturing and installation error. In order to more accurately evaluate the dynamic behavior of the elevator car, the compound vibration problems containing both random excitation and random parameters were studied. The deterministic part and random part of the acceleration response were derived by the perturbation theory, and the vibration image in the time domain and frequency domain were analyzed. The sensitivity expressions of each parameter to the system response were established in the random vibration system. The acceleration standard deviation due to random excitation was calculated by the pseudo excitation method. The acceleration standard deviation due to the random parameters was obtained according to the displacement response covariance matrix and random parameters covariance matrix. The discrete degree of random excitation and random parameters on the transverse acceleration of the car was analyzed in an example, and the influence degree of each parameter on acceleration responses was quantitatively described by calculating the response sensitivity of random parameters. This paper provides an effective method for the analysis of the vibration characteristics of the high speed elevator car system.
\end{abstract}

\section{Keywords}

high-speed elevator, transverse vibration, random parameters, perturbation theory, sensitivity

\footnotetext{
${ }^{1}$ College of Mechanical Engineering,

Tianjin University, Tianjin, China

${ }^{2}$ College of Mechanical and Electronic Engineering,

Shandong Jianzhu University, Jinan, China

*Corresponding author, e-mail: zhangqing1761@163.com
}

\section{Introduction}

In modern society, there are more and more high-rise buildings. As an essential means of transport in high-rise buildings, elevators have become faster, and the proportion of high-speed elevator (the speed $\geq 2.5 \mathrm{~m} / \mathrm{s}$ ) has increased year by year. The transverse vibration acceleration that is generated by the random excitation and random parameters has become a major factor affecting the ride comfort of the elevator. In recent years many scholars have studied transverse vibration of elevator cars. Feng et al. [1] established a dynamic model of the transverse vibration of an elevator car based on the rigid body dynamics theory, and she derived the differential equations based on Newton's laws of motion and the Euler equations. Chang et al. [2] established a four degree-of-freedom elevator system to study the excitation characteristics and the car dynamic response, and developed an active mass driver based on $\mathrm{H}_{\infty}$ direct output feedback control algorithm. Herrera et al. [3] considered the behavior of passengers in the car and established a model to analyze the influence of the car dynamic characteristics under different loading conditions. However, for objective random excitation and random parameters of an elevator car, most literature did not consider or approximate the deterministic parameter. In fact, random parameters not only affect the system of each mode of eigenvalues and eigenvectors, but also have an effect on the numerical characteristics of the response together with random excitation. So the study of dynamic response of the random parameter structure under random excitation is important for suppression of a vibration of elevator car, reliability sensitivity analysis, and safety assessment.

$\mathrm{Xu}$ et al. [4] analyzed the stochastic dynamic characteristics of beams under the stochastic material properties by the random factor method. However, the authors did not do this research combining the random excitation. Marcin et al. [5] solved the dynamic response of the truss structure by using the Taylor expansion stochastic finite element method. The stochastic finite element method needs to set up all kinds of random parameters corresponding to the stochastic finite element characteristic matrix, and it causes much inconvenience to its 
computer program design. Lasota et al. [6] obtained the digital characteristics of responses of the rotor shaft system by using the polynomial chaos method. Although the polynomial chaos method can quickly obtain the corresponding numerical characteristics, it can not very well solve problems combining the correlation between parameters. Therefore, it is necessary to find a convenient calculation method to makes it easy to design the calculation program. In this paper, a random perturbation method was used to derive the dynamic equation of the system response under random excitation and random parameters, and then the sensitivity expression of response was derived. The standard deviation of the acceleration response of the system was solved by establishing the displacement response covariance matrix and random parameters covariance matrix and combining with the pseudo excitation method.

\section{High-speed elevator car system dynamics model}

In order to solve the transverse acceleration response of a high speed elevator car system with random parameters under random excitation, a suitable model of the car's dynamic model was established and the differential equation of the car's vibration was derived. In the high-speed elevator, in order to improve the ride comfort, there are a certain number of damping blocks between the car frame and the car, so they are an elastic connection. [7] In Fig. 1, a car vibration model is presented. The car frame is in contact with the guide rails by four guide wheel-guide shoe systems. The guide wheel-guide shoe system and damping block are simplified into a spring damping system [8]. The stiffness and damping of four guide wheel-guide shoe systems are $k_{1}$ and $c_{1}$, and the stiffness and damping of four damping blocks are $k_{2}$ and $c_{2}$. This system has four degrees of freedom, including the car frame's transverse translation and rotation around the center of mass, and the car's transverse translation and rotation around the center of mass. $O X Y$ is the coordinate system taking the system center $O$ of the equilibrium position as the origin. $l_{\mathrm{ai}}(\mathrm{i}=1, \ldots, 8)$ is the $Y$-coordinate of the car frame stress points in the coordinate system, and $l_{\text {bi }}(\mathrm{i}=5, \ldots, 8)$ is the $Y$-coordinate of the car stress points in the coordinate system. $l_{\mathrm{i}}(\mathrm{i}=1, \ldots, 4)$ are the random geometrical parameters, where $l_{1}=\left|l_{\mathrm{a} 1}\right|=\left|l_{\mathrm{a} 3}\right|, l_{2}=\left|l_{\mathrm{a} 2}\right|=\left|l_{\mathrm{a} 4}\right|, l_{3}=\left|l_{\mathrm{a} 5}\right|=\left|l_{\mathrm{a} 7}\right|$ and $l_{4}=\left|l_{\mathrm{a} 6}\right|=\left|l_{\mathrm{a} 8}\right|$. The car frame mass $m_{\mathrm{a}}$, moment of inertia $j_{\mathrm{a}}$, car mass $m_{\mathrm{b}}$ and moment of inertia $j_{\mathrm{b}}$ are the random mass parameters.

According to Newton's second law and the rigid body dynamics formula, the four degrees of freedom system's differential equations of motion can be expressed as:

$$
\boldsymbol{M} \ddot{\boldsymbol{X}}+\boldsymbol{C} \dot{\boldsymbol{X}}+\boldsymbol{K} \boldsymbol{X}=\boldsymbol{F}(t) .
$$

In which

$\boldsymbol{M}=\operatorname{diag}\left(m_{\mathrm{a}}, j_{\mathrm{a}}, m_{\mathrm{b}}, j_{\mathrm{b}}\right)$,

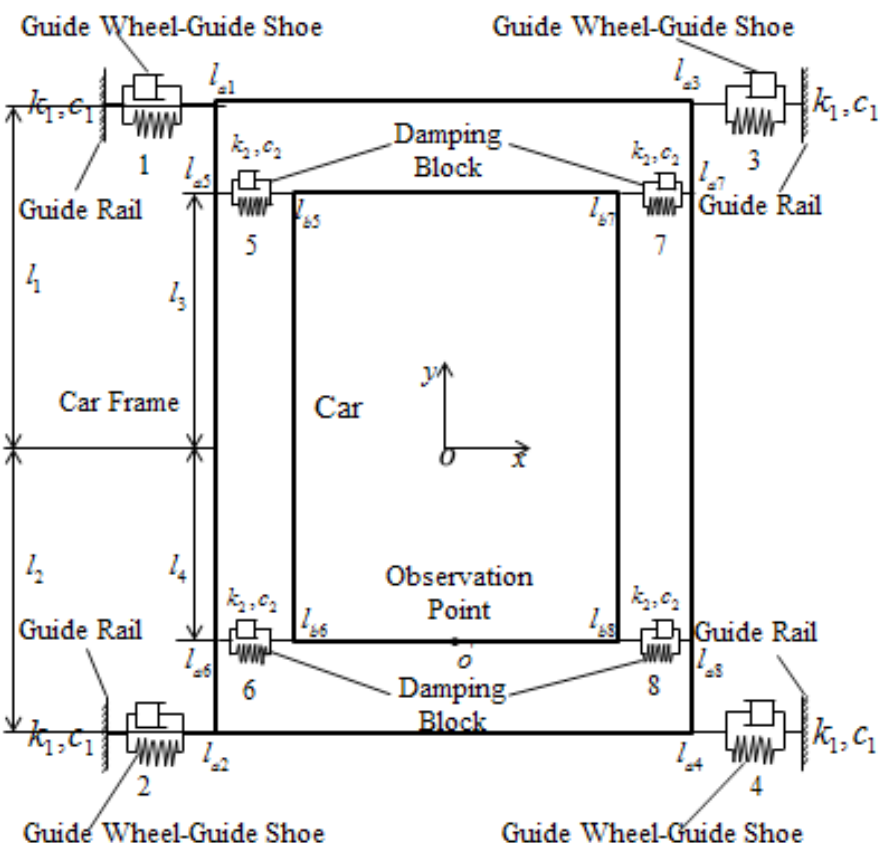

Fig. 1 Model of vibrations for elevator cabin systems

$$
\begin{aligned}
& \boldsymbol{C}=\left[\begin{array}{cc}
-4\left(c_{1}+c_{2}\right) & 2 c_{1}\left(l_{1}-l_{2}\right)+2 c_{2}\left(l_{3}-l_{4}\right) \\
2 c_{1}\left(l_{1}-l_{2}\right)+2 c_{2}\left(l_{3}-l_{4}\right) & -2 c_{1}\left(l_{1}^{2}+l_{2}^{2}\right)-2 c_{2}\left(l_{3}^{2}+l_{4}^{2}\right. \\
4 c_{2} & -2 c_{2}\left(l_{3}-l_{4}\right) \\
-2 c_{2}\left(l_{3}-l_{4}\right) & 2 c_{2}\left(l_{3}^{2}+l_{4}^{2}\right)
\end{array}\right. \\
& \left.\begin{array}{cc}
4 c_{2} & -2 c_{2}\left(l_{3}-l_{4}\right) \\
-2 c_{2}\left(l_{3}-l_{4}\right) & 2 c_{2}\left(l_{3}^{2}+l_{4}^{2}\right) \\
-4 c_{2} & 2 c_{2}\left(l_{3}-l_{4}\right) \\
2 c_{2}\left(l_{3}-l_{4}\right) & -2 c_{2}\left(l_{3}^{2}+l_{4}^{2}\right)
\end{array}\right]
\end{aligned}
$$$$
\boldsymbol{K}=\left[\begin{array}{cc}
4\left(k_{1}+k_{2}\right) & -2 k_{1}\left(l_{1}-l_{2}\right)-2 k_{2}\left(l_{3}-l_{4}\right. \\
-2 k_{1}\left(l_{1}-l_{2}\right)-2 k_{2}\left(l_{3}-l_{4}\right) & 2 k_{1}\left(l_{1}^{2}+l_{2}^{2}\right)+2 k_{2}\left(l_{3}^{2}+l_{4}^{2}\right. \\
-4 k_{2} & 2 k_{2}\left(l_{3}-l_{4}\right) \\
2 k_{2}\left(l_{3}-l_{4}\right) & -2 k_{2}\left(l_{3}^{2}+l_{4}^{2}\right)
\end{array}\right.
$$

$$
\left.\begin{array}{cc}
-4 k_{2} & 2 k_{2}\left(l_{3}-l_{4}\right) \\
2 k_{2}\left(l_{3}-l_{4}\right) & -2 k_{2}\left(l_{3}^{2}+l_{4}^{2}\right) \\
4 k_{2} & -2 k_{2}\left(l_{3}-l_{4}\right) \\
-2 k_{2}\left(l_{3}-l_{4}\right) & 2 k_{2}\left(l_{3}^{2}+l_{4}^{2}\right)
\end{array}\right],
$$

$\boldsymbol{X}=\left[\begin{array}{l}x_{1} \\ \theta_{1} \\ x_{2} \\ \theta_{2}\end{array}\right]$.

$\boldsymbol{F}(t)$ is random excitation due to the rail irregularity degree, and it can be expressed as: 


$$
\boldsymbol{F}(t)=\left[\begin{array}{c}
4 k_{1} \sum_{i=1}^{4} x_{\mathrm{di}}(t)+4 c_{1} \sum_{i=1}^{4} \dot{x}_{\mathrm{di}}(t) \\
2 k_{1}\left(l_{1}-l_{2}\right) \sum_{i=1}^{4} x_{\mathrm{di}}(t)+2 c_{1}\left(l_{1}-l_{2}\right) \sum_{i=1}^{4} \dot{x}_{\mathrm{di}}(t) \\
0 \\
0
\end{array}\right],
$$

$x_{\mathrm{di}}(t)(\mathrm{i}=1, \ldots, 4)$ are the four guide wheels' position which change over time.

\section{The transverse vibration response of high-speed elevator car system and analysis of parameter sensitivity}

In this section, the transverse vibration dynamic response of the car system is discussed by using the random perturbation method [9-12]. Since this system has ma, $j_{\mathrm{a}}, m_{\mathrm{b}}, j_{\mathrm{b}}, k_{1}, k_{2}, c_{1}, c_{2}$, $l_{1}, l_{2}, l_{3}$ and $l_{4}$ a total of 12 random parameters, the mass matrix $\boldsymbol{M}$, damping matrix $\boldsymbol{C}$, and stiffness matrix $\boldsymbol{K}$ in the differential equations of motion also have randomness, and the following transformation is needed:

$$
\begin{gathered}
\boldsymbol{M}=\boldsymbol{M}_{\mathrm{d}}+\varepsilon \boldsymbol{M}_{\mathrm{r}}, \\
\boldsymbol{C}=\boldsymbol{C}_{\mathrm{d}}+\varepsilon \boldsymbol{C}_{\mathrm{r}}, \\
\boldsymbol{K}=\boldsymbol{K}_{\mathrm{d}}+\varepsilon \boldsymbol{K}_{\mathrm{r}}, \\
\boldsymbol{X}=\boldsymbol{X}_{\mathrm{d}}+\varepsilon \boldsymbol{X}_{\mathrm{r}}, \\
\boldsymbol{F}(t)=\boldsymbol{F}_{\mathrm{d}}(t)+\varepsilon \boldsymbol{F}_{\mathrm{r}}(t) .
\end{gathered}
$$

Where $\varepsilon$ is a small parameter, and subscript $d$ and subscript $\mathrm{r}$ denote the deterministic parts and random parts of random parameters, and $\boldsymbol{M}_{\mathrm{d}}, \boldsymbol{C}_{\mathrm{d}}, \ldots$ are the main items. $\varepsilon \boldsymbol{M}_{\mathrm{r}}, \varepsilon \boldsymbol{C}_{\mathrm{r}}, \ldots$ are small items standing for the influence of random parts on the random parameters, and they are known as "perturbations", and their mean of the random parts is zero. Eq. (3)-Eq. (7) are imported into the original differential equations Eq. (1), and expanded and compared with factor $\varepsilon$ at the same power. Omitting higher-order terms above $O\left(\varepsilon^{2}\right)$ the following equations are obtained:

$$
\begin{aligned}
& \varepsilon^{0}: \boldsymbol{M}_{\mathrm{d}} \ddot{\boldsymbol{X}}_{\mathrm{d}}+\boldsymbol{C}_{\mathrm{d}} \dot{\boldsymbol{X}}_{\mathrm{d}}+\boldsymbol{K}_{\mathrm{d}} \boldsymbol{X}=\boldsymbol{F}_{\mathrm{d}}(t), \\
& \varepsilon^{1}: \boldsymbol{M}_{\mathrm{d}} \ddot{\boldsymbol{X}}_{\mathrm{r}}+\boldsymbol{C}_{\mathrm{d}} \dot{\boldsymbol{X}}_{\mathrm{r}}+\boldsymbol{K}_{\mathrm{d}} \boldsymbol{X}_{\mathrm{r}} \\
& =\boldsymbol{F}_{\mathrm{r}}(t)-\left(\boldsymbol{M}_{\mathrm{r}} \ddot{\boldsymbol{X}}_{\mathrm{d}}+\boldsymbol{C}_{\mathrm{r}} \ddot{\boldsymbol{X}}_{\mathrm{d}}+\boldsymbol{K}_{\mathrm{r}} \boldsymbol{X}_{\mathrm{d}}\right) .
\end{aligned}
$$

By solving Eq. (8) the deterministic parts of response $\ddot{\boldsymbol{X}}_{d}, \dot{\boldsymbol{X}}_{\mathrm{d}}$, and $\boldsymbol{X}_{\mathrm{d}}$ can be obtained. By solving Eq. (9) the random parts of response $\ddot{\boldsymbol{X}}_{\mathrm{r}}, \dot{\boldsymbol{X}}_{\mathrm{r}}$, and $\boldsymbol{X}_{\mathrm{r}}$ can be obtained. The center of the car floor is regarded as observation point, and the transverse response of the observation point can be obtained by pre-multiplying transformation matrix $\boldsymbol{T}=\left[\begin{array}{llll}0 & 0 & 1 & l_{4}\end{array}\right]$. With the aid of MATLAB fast Fourier transform, images in the frequency domain of each respond can be obtained.
It can be seen that the random parts of response $\ddot{\boldsymbol{X}}_{\mathrm{r}}, \dot{\boldsymbol{X}}_{\mathrm{r}}$, and $\boldsymbol{X}_{\mathrm{r}}$ consist of two parts from formula (9). $\boldsymbol{X}_{\mathrm{r} 1}$ represents the displacement response due to random excitation, and $\boldsymbol{X}_{\mathrm{r} 2}$ represents the displacement response due to random parameters, and they satisfy the following equation:

$$
\boldsymbol{X}_{\mathrm{r}}=\boldsymbol{X}_{\mathrm{r} 1}+\boldsymbol{X}_{\mathrm{r} 2} \text {. }
$$

Equation (9) can be divided into two equations:

$$
\begin{gathered}
\boldsymbol{M}_{\mathrm{d}} \ddot{\boldsymbol{X}}_{\mathrm{r} 1}+\boldsymbol{C}_{\mathrm{d}} \dot{\boldsymbol{X}}_{\mathrm{r} 1}+\boldsymbol{K}_{\mathrm{d}} \boldsymbol{X}_{\mathrm{r} 1}=\boldsymbol{F}_{\mathrm{r}}(t), \\
\boldsymbol{M}_{\mathrm{d}} \ddot{\boldsymbol{X}}_{\mathrm{r} 2}+\boldsymbol{C}_{\mathrm{d}} \dot{\boldsymbol{X}}_{\mathrm{r} 2}+\boldsymbol{K}_{\mathrm{d}} \boldsymbol{X}_{\mathrm{r} 2}=-\left(\boldsymbol{M}_{\mathrm{r}} \ddot{\boldsymbol{X}}_{\mathrm{d}}+\boldsymbol{C}_{\mathrm{r}} \ddot{\boldsymbol{X}}_{\mathrm{d}}+\boldsymbol{K}_{\mathrm{r}} \boldsymbol{X}_{\mathrm{d}}\right) .
\end{gathered}
$$

Structural dynamic response sensitivity analysis is often used to assess the degree of influence of the changes in structural parameters on the response. The dynamic performance of the structure can be improved according to this sensitivity. It is an important part of structural dynamic optimization design. In order to facilitate solving Eq. (12) and derive the system dynamic response's sensitivity sector $S(\ddot{X}), S(\dot{X})$, and $\boldsymbol{S}(\boldsymbol{X})$, when the parameters' random parts $b_{\mathrm{ri}}$ are much smaller than the deterministic parts $b_{\mathrm{di}}, \boldsymbol{M}_{\mathrm{r}}, \boldsymbol{C}_{\mathrm{r}}, \boldsymbol{K}_{\mathrm{r}}, \ddot{\boldsymbol{X}}_{\mathrm{r} 2}$, $\dot{\boldsymbol{X}}_{\mathrm{r} 2}$, and $\boldsymbol{X}_{\mathrm{r} 2}$ are expanded into the Taylor series in the vicinity of $b_{\mathrm{di}}(\mathrm{i}=1,2, \ldots, \mathrm{m})$, and substituted into Eq. (12), and comparing the $b_{r i}$ coefficients, the following equation is obtained:

$$
\begin{aligned}
& \boldsymbol{M}_{\mathrm{d}} \boldsymbol{S}_{\mathrm{i}}(\ddot{\boldsymbol{X}})+\boldsymbol{C}_{\mathrm{d}} \boldsymbol{S}_{\mathrm{i}}(\dot{\boldsymbol{X}})+\boldsymbol{K}_{\mathrm{d}} \boldsymbol{S}_{\mathrm{i}}(\boldsymbol{X}) \\
& =-\left(\frac{\partial \boldsymbol{M}}{\partial b_{\mathrm{i}}} \ddot{\boldsymbol{X}}_{\mathrm{d}}+\frac{\partial \boldsymbol{C}}{\partial b_{\mathrm{i}}} \dot{\boldsymbol{X}}_{\mathrm{d}}+\frac{\partial \boldsymbol{K}}{\partial b_{\mathrm{i}}} \boldsymbol{X}_{\mathrm{d}}\right) .
\end{aligned}
$$

In which

$\boldsymbol{S}_{\mathrm{i}}(\ddot{\boldsymbol{X}})=\frac{\partial \ddot{\boldsymbol{X}}_{\mathrm{d}}}{\partial b_{\mathrm{i}}}, \boldsymbol{S}_{\mathrm{i}}(\dot{\boldsymbol{X}})=\frac{\partial \dot{\boldsymbol{X}}_{\mathrm{d}}}{\partial b_{\mathrm{i}}}, \quad \boldsymbol{S}_{\mathrm{i}}(\boldsymbol{X})=\frac{\partial \boldsymbol{X}_{\mathrm{d}}}{\partial b_{\mathrm{i}}}$.

The system dynamic response's sensitivity vector $S(\ddot{X})$, $\boldsymbol{S}(\dot{\boldsymbol{X}})$ and $\boldsymbol{S}(\boldsymbol{X})$ are obtained by solving Eq. (13), and the random parts of the system response can be obtained by substituting them into the Taylor expansion of $\ddot{\boldsymbol{X}}_{\mathrm{r} 2}, \dot{\boldsymbol{X}}_{\mathrm{r} 2}$, and $\boldsymbol{X}_{\mathrm{r} 2}$.

$$
\begin{aligned}
& \ddot{\boldsymbol{X}}_{\mathrm{r} 2}=\sum_{\mathrm{i}=1}^{\mathrm{m}} \boldsymbol{S}_{\mathrm{i}}(\ddot{\boldsymbol{X}}) b_{\mathrm{ri}}, \\
& \dot{\boldsymbol{X}}_{\mathrm{r} 2}=\sum_{\mathrm{i}=1}^{\mathrm{m}} \boldsymbol{S}_{\mathrm{i}}(\dot{\boldsymbol{X}}) b_{\mathrm{ri}}, \\
& \boldsymbol{X}_{\mathrm{r} 2}=\sum_{\mathrm{i}=1}^{\mathrm{m}} \boldsymbol{S}_{\mathrm{i}}(\boldsymbol{X}) b_{\mathrm{ri}} .
\end{aligned}
$$

\section{Analysis of means and standard deviation of a high-speed elevator with random parameters}

The mean of the displacement response perturbation items is zero, which has the following expression:

$$
E(\boldsymbol{X})=E\left(\boldsymbol{X}_{\mathrm{d}}\right)+E\left(\varepsilon \boldsymbol{X}_{\mathrm{r}}\right)=\boldsymbol{X}_{\mathrm{d}}
$$


Similarly

$$
\begin{aligned}
& E(\dot{\boldsymbol{X}})=E\left(\dot{\boldsymbol{X}}_{\mathrm{d}}\right)+E\left(\varepsilon \dot{\boldsymbol{X}}_{\mathrm{r}}\right)=\dot{\boldsymbol{X}}_{\mathrm{d}}, \\
& E(\ddot{\boldsymbol{X}})=E\left(\ddot{\boldsymbol{X}}_{\mathrm{d}}\right)+E\left(\varepsilon \ddot{\boldsymbol{X}}_{\mathrm{r}}\right)=\ddot{\boldsymbol{X}}_{\mathrm{d}}
\end{aligned}
$$

The respond standard deviation due to random excitation $\boldsymbol{F}_{\mathrm{r}}(t)$ can be calculated by using the pseudo excitation method [13-17]. Assuming $\boldsymbol{F}_{\mathrm{r}}(t)$ is the ergodic random process, then $\ddot{\boldsymbol{X}}_{\mathrm{r} 1}, \dot{\boldsymbol{X}}_{\mathrm{r} 1}$, and $\boldsymbol{X}_{\mathrm{r} 1}$ also are the ergodic random process. According the random vibration theory, when the linear structure is subjected to multi-point stationary random excitations of which the Auto-spectral Density matrix is $\left[\boldsymbol{S}_{F_{\mathrm{r}} F_{\mathrm{r}}}(\omega)\right]$, the Auto-spectral Density of response $\ddot{\boldsymbol{X}}_{\mathrm{r} 1}$ is

$$
\left[\boldsymbol{S}_{\ddot{X}_{\mathrm{r} 1} \ddot{X}_{\mathrm{r} 1}}(\omega)\right]=\omega^{4}|H(\omega)|^{2}\left[\boldsymbol{S}_{F_{\mathrm{r}} F_{\mathrm{r}}}(\omega)\right] \text {. }
$$

$H(\omega)$ is frequency response. The frequency response connecting with the $n$-th mode is

$$
H_{\mathrm{n}}(\omega)=\left[1-\left(\frac{\omega}{\omega_{\mathrm{n}}}\right)^{2}+2 \xi \frac{\omega}{\omega_{\mathrm{n}}} i\right]^{-1} \quad(\mathrm{n}=1,2, \ldots, \mathrm{q}) .
$$

A pseudo excitation $\tilde{\boldsymbol{F}}_{\mathrm{r}}$ is constructed, which is $\left(\boldsymbol{S}_{F_{\mathrm{r}} F_{\mathrm{r}}}\right)^{1 / 2} e^{i \omega t}$, then the corresponding virtual response $\tilde{\ddot{X}}_{\mathrm{r} 1}$ is

$$
\tilde{\ddot{X}}_{\mathrm{r} 1}=\omega^{4}\left(\boldsymbol{S}_{F_{\mathrm{r}} F_{\mathrm{r}}}\right)^{1 / 2} H(\omega) e^{i \omega t} .
$$

The Auto-spectral Density expression of the response is derived:

$$
\left[\boldsymbol{S}_{\ddot{X}_{\mathrm{r} 1} \ddot{X}_{\mathrm{r} 1}}(\omega)\right]=\left[\tilde{\ddot{\boldsymbol{X}}}_{\mathrm{r} 1}\right]^{*} \cdot\left[\tilde{\ddot{\boldsymbol{X}}}_{\mathrm{r} 1}\right]^{\mathrm{T}}=\left|\tilde{\ddot{\boldsymbol{X}}}_{\mathrm{r} 1}\right|^{2}=\omega^{8}|H(\omega)|^{2}\left[\boldsymbol{S}_{F_{\mathrm{r} F}}(\omega)\right] .
$$

The acceleration response standard deviation is

$$
\sigma_{\ddot{X}_{\mathrm{r} 1}}=\sqrt{\varphi_{\ddot{X}_{\mathrm{r} 1}}^{2}-\mu_{\ddot{X}_{\mathrm{r} 1}}^{2}}=\sqrt{\frac{1}{2 \pi} \int_{-\infty}^{\infty}\left[\boldsymbol{S}_{\ddot{X}_{\mathrm{r} 1} \ddot{X}_{\mathrm{r} 1}}(\omega)_{(\mathrm{nn})}\right] d \omega .}
$$

$\left[\boldsymbol{S}_{\ddot{X}_{\mathrm{r} 1} \ddot{X}_{\mathrm{r} 1}}(\omega)_{(\mathrm{nn})}\right]$ is the column vector and its elements are formed of $\left[\boldsymbol{S}_{\ddot{X}_{\mathrm{r} 1} \ddot{X}_{\mathrm{r} 1}}(\omega)\right]$ 's diagonal elements.

For the standard deviation of random excitation $\boldsymbol{X}_{\mathrm{r} 2}$ due to random parameters, first the displacement response covariance matrix $\boldsymbol{N}_{\mathrm{x}}$, random parameters covariance matrix $\boldsymbol{N}_{\mathrm{b}}$, and displacement response sensitivity matrix $\left[\frac{\partial \boldsymbol{X}_{\mathrm{d}}}{\partial b}\right]$ are defined:

$$
\boldsymbol{N}_{\mathrm{x}}=\left[\begin{array}{cccc}
\operatorname{Var}\left(\boldsymbol{X}^{(1)}\right) & \operatorname{Cov}\left(\boldsymbol{X}^{(2)}, \boldsymbol{X}^{(1)}\right) & \cdots & \operatorname{Cov}\left(\boldsymbol{X}^{(\mathrm{k})}, \boldsymbol{X}^{(1)}\right) \\
\operatorname{Cov}\left(\boldsymbol{X}^{(2)}, \boldsymbol{X}^{(1)}\right) & \operatorname{Var}\left(\boldsymbol{X}^{(2)}\right) & \cdots & \operatorname{Cov}\left(\boldsymbol{X}^{(\mathrm{k})}, \boldsymbol{X}^{(2)}\right) \\
\vdots & \vdots & \ddots & \vdots \\
\operatorname{Cov}\left(\boldsymbol{X}^{(\mathrm{k})}, \boldsymbol{X}^{(1)}\right) & \operatorname{Cov}\left(\boldsymbol{X}^{(\mathrm{k})}, \boldsymbol{X}^{(2)}\right) & \cdots & \operatorname{Var}\left(\boldsymbol{X}^{(\mathrm{k})}\right)
\end{array}\right]
$$

$$
\boldsymbol{N}_{\mathrm{b}}=\left[\begin{array}{cccc}
\operatorname{Var}\left(b_{1}\right) & \operatorname{Cov}\left(b_{2}, b_{1}\right) & \cdots & \operatorname{Cov}\left(b_{\mathrm{m}}, b_{1}\right) \\
\operatorname{Cov}\left(b_{2}, b_{1}\right) & \operatorname{Var}\left(b_{2}\right) & \cdots & \operatorname{Cov}\left(b_{\mathrm{m}}, b_{2}\right) \\
\vdots & \vdots & \ddots & \vdots \\
\operatorname{Cov}\left(b_{\mathrm{m}}, b_{1}\right) & \operatorname{Cov}\left(b_{\mathrm{m}}, b_{2}\right) & \cdots & \operatorname{Var}\left(b_{\mathrm{m}}\right)
\end{array}\right]
$$

$$
\left[\frac{\partial \boldsymbol{X}_{\mathrm{d}}}{\partial b}\right]=\left[\begin{array}{llll}
\frac{\partial \boldsymbol{X}_{\mathrm{d}}}{\partial b_{1}} & \frac{\partial \boldsymbol{X}_{\mathrm{d}}}{\partial b_{2}} & \cdots & \frac{\partial \boldsymbol{X}_{\mathrm{d}}}{\partial b_{\mathrm{m}}}
\end{array}\right],
$$

$\operatorname{Var}\left(X^{(\mathrm{k})}\right)$ represents the variance of the $k_{\text {th }}$ element in vector $\boldsymbol{X}$, and Cov represents covariance. The following equation is obtained:

$$
\boldsymbol{N}_{\mathrm{x}}=\left[\frac{\partial \boldsymbol{X}_{\mathrm{d}}}{\partial b}\right] \boldsymbol{N}_{\mathrm{b}}\left[\frac{\partial \boldsymbol{X}_{\mathrm{d}}}{\partial b}\right]^{\mathrm{T}}
$$

Solving Eq. (27), the standard deviation of the displacement response is obtained:

$$
\sigma_{x_{\mathrm{r} 2}}^{i}=\left(\sum_{\mathrm{j}=1}^{\mathrm{m}} \sum_{\mathrm{k}=1}^{\mathrm{m}} \frac{\partial \boldsymbol{X}_{\mathrm{d}}^{\mathrm{i}}}{\partial b_{\mathrm{j}}} \frac{\partial \boldsymbol{X}_{\mathrm{d}}^{\mathrm{i}}}{\partial b_{\mathrm{k}}} \sigma_{\mathrm{bj}} \sigma_{\mathrm{bk}} \rho_{\mathrm{jk}}\right)^{1 / 2},
$$

The $\sigma_{x}^{i}$ is the standard deviation $\left[\operatorname{Var}\left(\boldsymbol{X}^{(i)}\right]^{1 / 2}\right.$ of the $\mathrm{i}_{\text {th }}$ element in vector $\boldsymbol{X}, p_{j k}$ is the correlation coefficient of $b_{\mathrm{j}}$ and $b_{\mathrm{k}}$, and $\sigma_{\mathrm{b}}$ is the standard deviation of $b_{\mathrm{j}}$.

Similarly, the standard deviation of the velocity response and acceleration response is obtained:

$$
\begin{aligned}
& \sigma_{\dot{x}_{\mathrm{r} 2}}^{i}=\left(\sum_{\mathrm{j}=1}^{\mathrm{m}} \sum_{\mathrm{k}=1}^{\mathrm{m}} \frac{\partial \dot{\boldsymbol{X}}_{\mathrm{d}}^{\mathrm{i}}}{\partial b_{\mathrm{j}}} \frac{\partial \dot{\boldsymbol{X}}_{\mathrm{d}}^{\mathrm{i}}}{\partial b_{\mathrm{k}}} \sigma_{\mathrm{bj}} \sigma_{\mathrm{bk}} \rho_{\mathrm{jk}}\right)^{1 / 2}, \\
& \sigma_{\ddot{x}_{\mathrm{r} 2}}^{i}=\left(\sum_{\mathrm{j}=1}^{\mathrm{m}} \sum_{\mathrm{k}=1}^{\mathrm{m}} \frac{\partial \ddot{\boldsymbol{X}}_{\mathrm{d}}^{\mathrm{i}}}{\partial b_{\mathrm{j}}} \frac{\partial \ddot{\boldsymbol{X}}_{\mathrm{d}}^{\mathrm{i}}}{\partial b_{\mathrm{k}}} \sigma_{\mathrm{bj}} \sigma_{\mathrm{bk}} \rho_{\mathrm{jk}}\right)^{1 / 2} .
\end{aligned}
$$

In summary, the car transverse acceleration response standard deviation is

$$
\sigma_{\ddot{x}}=\sqrt{\sigma_{\ddot{x}_{\mathrm{r} 1}}^{2}+\sigma_{\ddot{x}_{\mathrm{r} 2}}^{2}} \text {. }
$$

It can be seen that as long as the standard deviation of the system architecture random parameters and their correlation coefficients are given, the standard deviation of the response can be obtained. This makes it easy to apply it to engineering practice. Simultaneously, in calculating the response sensitivity, only the required degree of freedom is chosen, so as to avoid a large amount of computation.

\section{Case analysis}

A high-speed elevator, with a speed of $5 \mathrm{~m} / \mathrm{s}$, was simplified into the model as shown in Fig. 1. The means and standard deviations of random parameters are shown in Table 1. It was assumed that the random parameters are independent and subject to normal distribution, and their coefficient of variation $\mathrm{CV}=0.05$.

Acommon pulse excitation was exerted on all guide wheels as the excitation's deterministic part $\boldsymbol{F}_{\mathrm{d}}$. A single rail length was $5 \mathrm{~m}$. The excitation is shown in Fig. 2.

\subsection{The calculation of the high-speed elevator car system transverse acceleration response}

Solving the response expression Eq. (8) by using Wilson- $\theta$ $[18,19]$, the acceleration response $\ddot{\boldsymbol{X}}_{\mathrm{d}}$ is obtained. Then the observation point acceleration $\ddot{x}_{\mathrm{d}}$ in the $\mathrm{x}$ direction is obtained 
Table 1 The parameters' means and standard deviation of the elevator cabin system

\begin{tabular}{llllllll}
\hline & Variable $b_{\mathrm{j}}$ & Mean $\mathrm{D} b_{\mathrm{j}}$ & Standard Deviation ${ }_{\mathrm{\sigma}} \mathrm{bj}$ & & Variable $b_{\mathrm{j}}$ & Means $\mathrm{D} b_{\mathrm{j}}$ & Standard Deviation $\sigma_{\mathrm{bj}}$ \\
\hline$b_{1}$ & $m_{\mathrm{a}} / \mathrm{kg}$ & 750 & 37.5 & $b_{7}$ & $c_{\mathrm{a}} /\left(\mathrm{N} \cdot \mathrm{s} / \mathrm{m}^{-1}\right)$ & 120 & 6 \\
$b_{2}$ & $j_{\mathrm{a}} /\left(\mathrm{kg} \cdot \mathrm{m}^{2}\right)$ & 3000 & 150 & $b_{8}$ & $c_{\mathrm{b}} /\left(\mathrm{N} \cdot \mathrm{s} / \mathrm{m}^{-1}\right)$ & 320 & 16 \\
$b_{3}$ & $m_{\mathrm{b}} / \mathrm{kg}$ & 1200 & 60 & $b_{9}$ & $l_{1} / \mathrm{m}$ & 1.6 & 0.08 \\
$b_{4}$ & $j_{\mathrm{b}} /\left(\mathrm{kg} \cdot \mathrm{m}^{2}\right)$ & 1300 & 65 & $b_{10}$ & $l_{2} / \mathrm{m}$ & 1.4 & 0.07 \\
$b_{5}$ & $k_{\mathrm{a}} /\left(\mathrm{N} \cdot \mathrm{m}^{-1}\right)$ & 10000 & 500 & $b_{11}$ & $l_{3} / \mathrm{m}$ & 1.2 & 0.06 \\
$b_{6}$ & $k_{\mathrm{b}} /\left(\mathrm{N} \cdot \mathrm{m}^{-1}\right)$ & 20000 & 1000 & $b_{12}$ & $l_{4} / \mathrm{m}$ & 1.0 & 0.05 \\
\hline
\end{tabular}

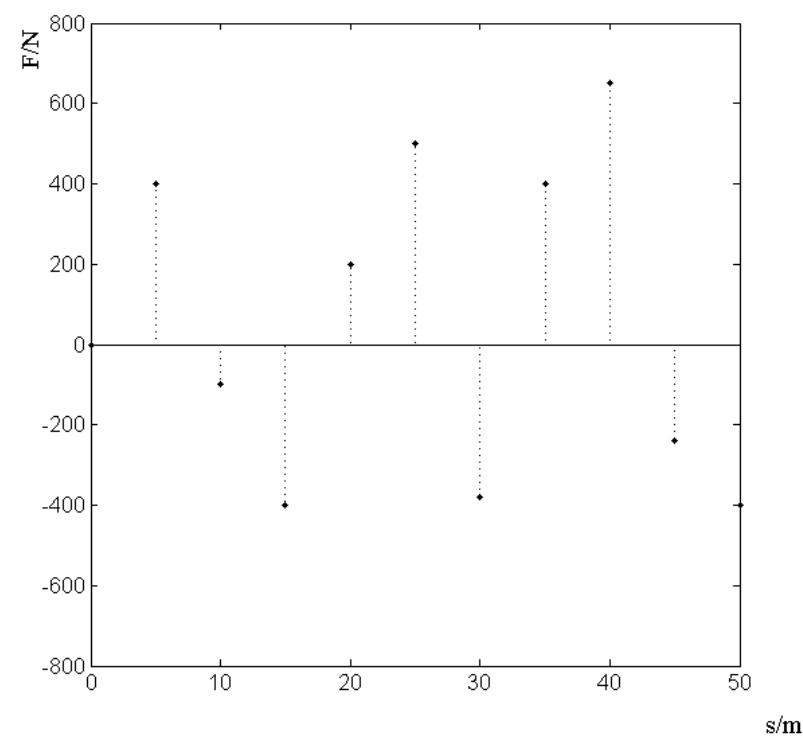

Fig. 2 The common pulse excitation caused by guide rails

by letting the acceleration response $\ddot{X}_{\mathrm{d}}$ pre-multiply the transformation matrix $\boldsymbol{T}$, as shown in Fig. 3. The White Gaussian Noise (its standard deviation $\sigma=20 \mathrm{~N}$, letting the whole excitation's coefficient of variation $\mathrm{CV}=0.05$ ) is defined of which the Power Spectral Density is $S(\omega)=n_{0} / 2=400 \mathrm{~W} / \mathrm{Hz}$. The transverse acceleration caused by the randomness of the excitation is obtained by solving Eq. (11), and pre-multiplying the transformation matrix $\boldsymbol{T}$ and superimposing over $\ddot{x}_{\mathrm{d}}$. Then the observation point's transverse acceleration $\ddot{x}_{\mathrm{d}+\mathrm{r}_{\mathrm{i}}}$ with the deterministic parameters under the random excitation is obtained, as shown in Fig. 4. The transverse acceleration $\ddot{\boldsymbol{X}}_{\mathrm{r} 2}$ caused by the randomness of parameters is obtained by solving Eq. (13) and substituting it into Eq. (14), and pre-multiplying the transformation matrix $\boldsymbol{T}$ and superimposing over $\ddot{x}_{\mathrm{d}+\mathrm{r}_{\mathrm{i}}}$. Then the observation point's transverse acceleration $\ddot{x}_{\mathrm{d}+r_{1}+r_{2}}$ with random parameters under the random excitation is obtained, as shown in Fig. 5.

With the help of MATLAB, $\ddot{x}_{\mathrm{d}}, \ddot{x}_{\mathrm{d}+\mathrm{r}_{1}}$, and $\ddot{x}_{\mathrm{d}+\mathrm{r}_{2}}$ are transformed into a Fourier series, and the images of $\ddot{x}_{\mathrm{d}}, \ddot{x}_{\mathrm{d}+\mathrm{r}_{\mathrm{i}}}$, and $\ddot{x}_{\mathrm{d}+\mathrm{r}_{2}}$ in the frequency domains are shown in Fig. 6-Fig. 8.

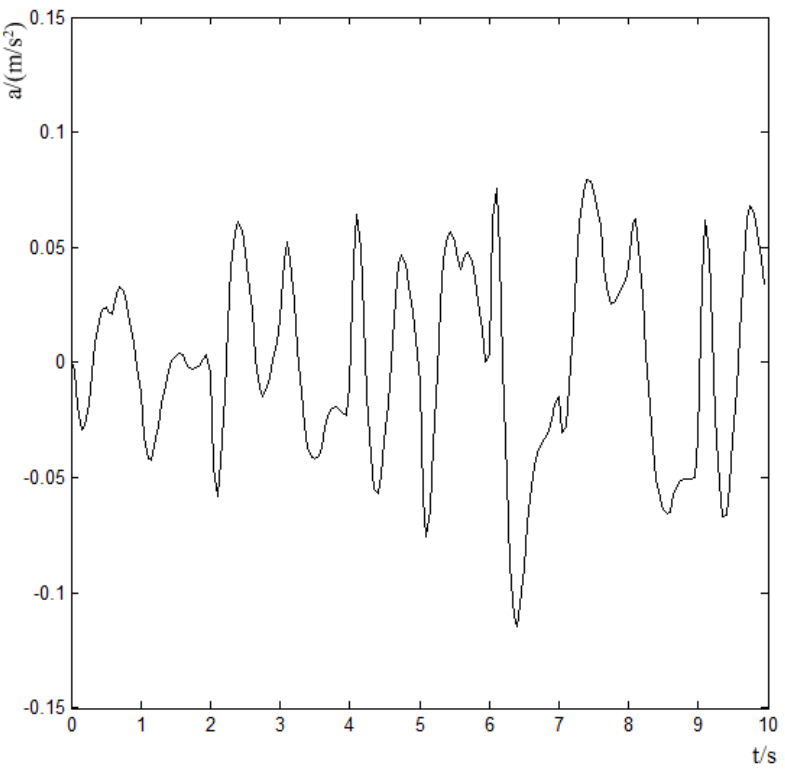

Fig. 3 Deterministic part of acceleration response of the observation point

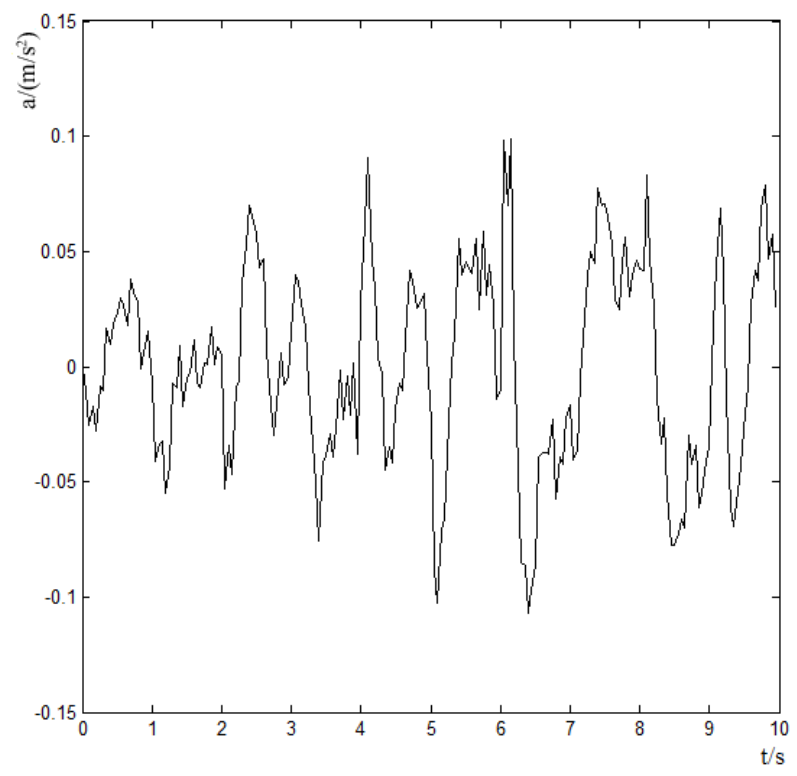

Fig. 4 Car system acceleration response with deterministic parameters under random excitation 


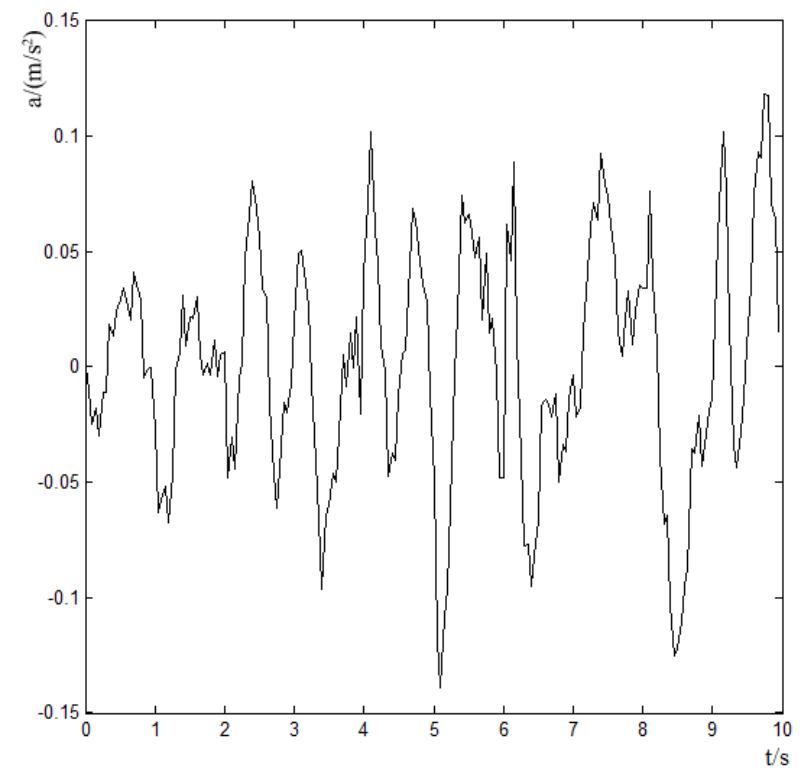

Fig. 5 Car system acceleration response with random parameters under random excitation

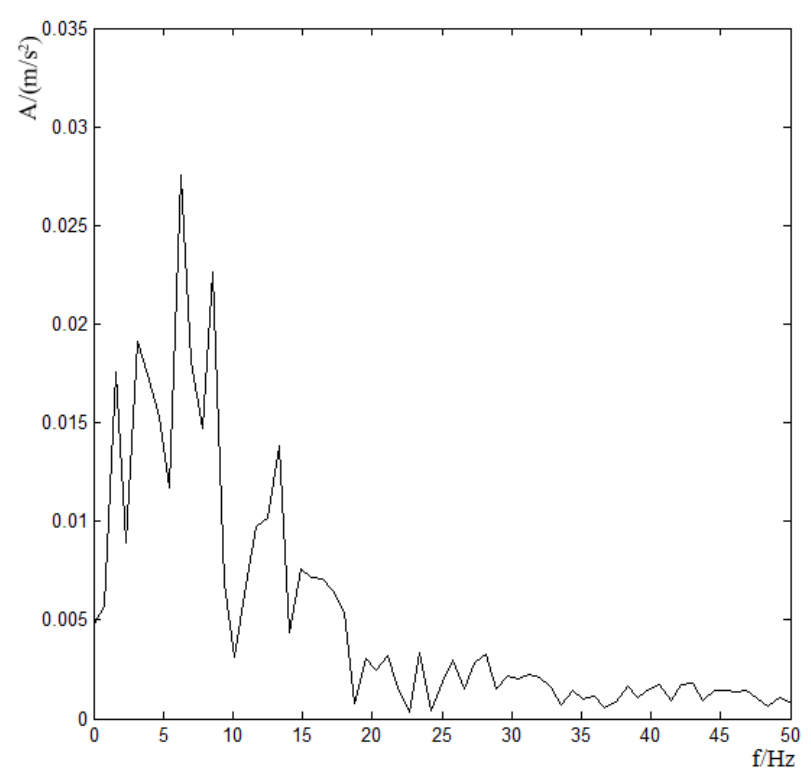

Fig. 6 Frequency domain image of deterministic part of the observation point acceleration response

Comparing Fig. 3-5, when the randomness of excitation and parameters are not considered, the image of the observation point's transverse acceleration shows a smoother curve in the time domain. After considering the randomness of excitation and parameters, the acceleration image shows an irregular jagged curve, and the maximum acceleration increased $21.4 \%$. It can be seen that the randomness of the guide rails' excitation and parameters have an impact on the transverse acceleration of the car, and the comfort is reduced. Comparing Fig. 6-8, in the frequency domain image, the maximum amplitude component is generally concentrated in the low-frequency range of $5 \mathrm{~Hz}$.

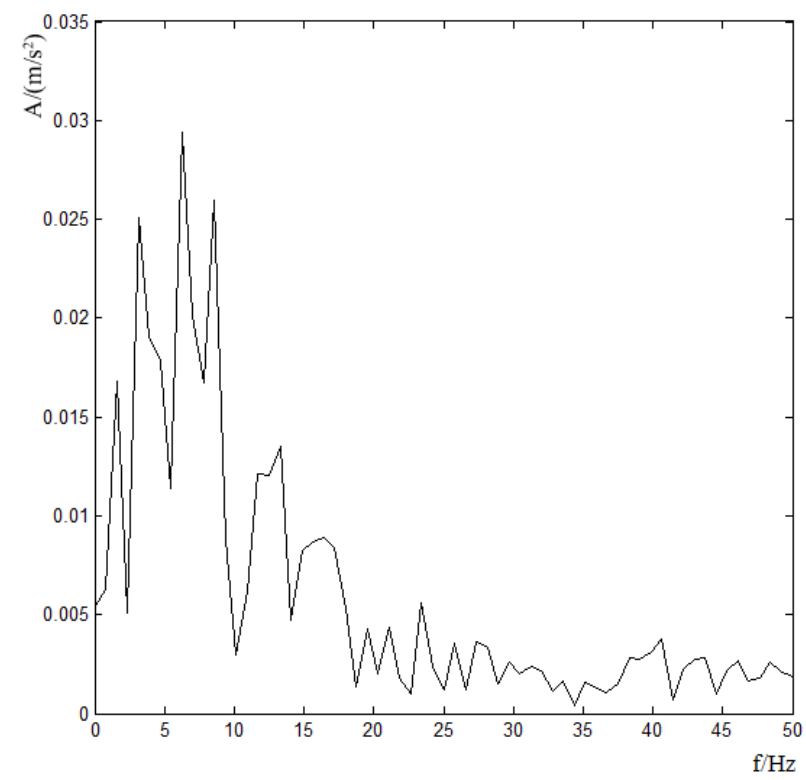

Fig. 7 Frequency domain image of the car system acceleration response with deterministic parameters under random excitation

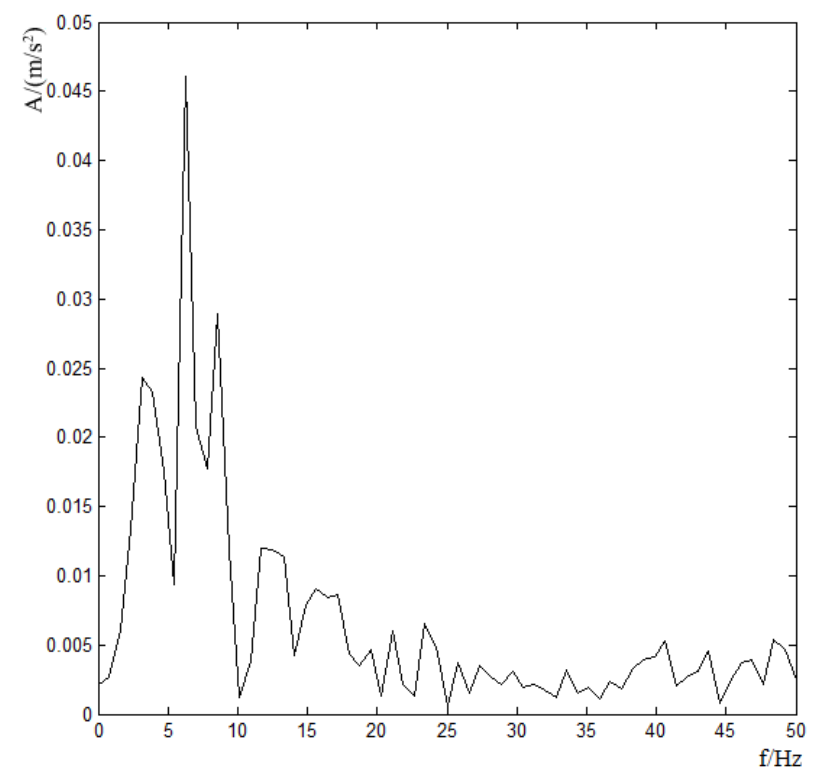

Fig. 8 Frequency domain image of the car system acceleration response with random parameters under random excitation

The randomness of the guide rails' excitation and parameters will only increase the amplitude, while it has little influence on the maximum amplitude frequency.

\subsection{Analysis of Acceleration Response Sensitivity}

The acceleration response's sensitivity vector $\boldsymbol{S}(\ddot{\boldsymbol{X}})$ is obtained by solving Eq. (13), and the acceleration response's sensitivity vector of the observation point is obtained by pre-multiplying the transformation matrix $\boldsymbol{T}$. The root mean square $s_{i}(\ddot{x})_{r m s}$ of each response sensitivity is calculated, and the results are shown in the Table 2. 
Table 2 The root mean square of respond sensitivity

\begin{tabular}{llll}
\hline Parameter & Sensitivity RMS & Parameter & Sensitivity RMS \\
\hline $\mathrm{b}_{1}\left(\mathrm{~m}_{\mathrm{a}}\right)$ & $5.234 \mathrm{e}-05$ & $\mathrm{~b}_{7}\left(\mathrm{c}_{1}\right)$ & $3.891 \mathrm{e}-05$ \\
$\mathrm{~b}_{2}\left(\mathrm{j}_{\mathrm{a}}\right)$ & $6.105 \mathrm{e}-06$ & $\mathrm{~b}_{8}\left(\mathrm{c}_{2}\right)$ & $3.641 \mathrm{e}-05$ \\
$\mathrm{~b}_{3}\left(\mathrm{~m}_{\mathrm{b}}\right)$ & $5.758 \mathrm{e}-05$ & $\mathrm{~b}_{9}\left(\mathrm{l}_{1}\right)$ & $2.983 \mathrm{e}-02$ \\
$\mathrm{~b}_{4}\left(\mathrm{j}_{\mathrm{b}}\right)$ & $1.344 \mathrm{e}-05$ & $\mathrm{~b}_{10}\left(1_{2}\right)$ & $4.146 \mathrm{e}-02$ \\
$\mathrm{~b}_{5}\left(\mathrm{k}_{1}\right)$ & $1.235 \mathrm{e}-05$ & $\mathrm{~b}_{11}\left(1_{3}\right)$ & $3.882 \mathrm{e}-02$ \\
$\mathrm{~b}_{6}\left(\mathrm{k}_{2}\right)$ & $4.424 \mathrm{e}-06$ & $\mathrm{~b}_{12}\left(1_{4}\right)$ & $7.174 \mathrm{e}-02$ \\
\hline
\end{tabular}

As can be seen from the table, the response sensitivities of geometrical parameters $l_{1}, l_{2}, l_{3}$, and $l_{4}$ are much larger than other parameters, and should be treated as random parameters. In addition, the response sensitivities of other parameters are low and can be used as the deterministic parameters.

\subsection{Analysis of the Observation Point's Mean and Standard Deviation}

The acceleration response of $6 \mathrm{~s}-7 \mathrm{~s}$ in which the amplitude is large was selected as the research object. The deterministic response $\ddot{x}_{\mathrm{d}}$ was regarded as the acceleration response mean $\overline{\ddot{x}}$. The standard deviation $\sigma_{\ddot{x}_{\mathrm{r} 1}}$ caused by the randomness of the guide rails' excitation is obtained by solving Eq. (23). The standard deviation $\sigma_{\ddot{x}_{\mathrm{r} 2}}$ caused by the randomness of parameters is obtained by solving Eq. (30). There are substituted into Eq. (31), and the standard deviation $\sigma_{\ddot{x}}$ of the acceleration response is obtained. The coefficient of variation $\mathrm{CV}$ is calculated. The results are shown in Table 3.

Table 3 The mean, the standard deviation, and the coefficient of variation of the acceleration response

\begin{tabular}{llll}
\hline $\begin{array}{c}\text { Time } \\
\mathrm{t} / \mathrm{s}\end{array}$ & $\begin{array}{l}\text { Mean } \\
\ddot{x} /\left(\mathrm{m} / \mathrm{s}^{2}\right)\end{array}$ & $\begin{array}{l}\text { Standard Deviation } \\
\sigma_{\ddot{x}} /\left(\mathrm{m} / \mathrm{s}^{2}\right)\end{array}$ & $\begin{array}{l}\text { Coefficient } \\
\text { of Variation CV }\end{array}$ \\
\hline 6.0 & 0.0140 & 0.0096 & 0.6857 \\
6.2 & 0.0473 & 0.0059 & 0.1247 \\
6.4 & -0.1100 & 0.0110 & 0.1000 \\
6.6 & -0.0697 & 0.0102 & 0.1463 \\
6.8 & -0.0357 & 0.0109 & 0.3053 \\
7.0 & -0.0176 & 0.0108 & 0.6136 \\
\hline
\end{tabular}

As can be seen from the table, the mean of the CV of the acceleration response is 0.33 in the case of the $\mathrm{CV}$ of random excitation and random parameters is 0.05 , and comparing the image of the deterministic part of observation point acceleration response and the total acceleration image, it can be shown that the response of the discrete degree was large, and the randomness of the guide rails' excitation and the parameters have an obvious effect on the acceleration of the center of the elevator car.

\section{Conclusions}

(1) In this paper, an elevator car vibration model with random parameters under random excitation was established, and the dynamic response expressions for deterministic random parts of the arbitrary point were established by using the stochastic perturbation theory. It was discovered that the random excitation and the random parameters let the acceleration response show a more discrete state by the analysis in the image of the time domain and frequency domain.

(2) Application of the response sensitivity expression can solve the transverse acceleration response's sensitivity of each random parameter to the observation point. The acceleration sensitivity of geometrical parameters was much larger than the other parameters. For convenience of calculation, the random parameters that have a lower acceleration response sensitivity were simplified as the deterministic parameters. Only selected higher sensitivity parameter were treated as random parameters in order to improve the calculation accuracy. In the manufacturing and installation processes the parameters with high sensitivity should be strictly controlled.

(3) The acceleration response's mean and standard deviation caused by the randomness of excitation and parameters were calculated by the analysis of acceleration response digital features. They accurately reflect the degree of dispersion of the transverse acceleration respond of the car under the influence of the latter.

\section{References}

[1] Feng, Y. H., Zhang, J. W. "Modeling and robust control of horizontal vibrations for high-speed elevator." Journal of Vibration and Control. 15(9), pp. 1375-1396. 2009.

https://doi.org/10.1177/1077546308096102

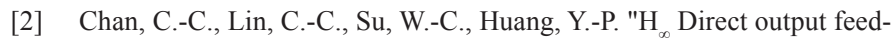
back control of high-speed elevator systems." In: Proceedings of the ASME 2011 Pressure Vessels \& Piping Division Conference, Baltimore, USA, July 17-21, 2011. pp. 289-296.

https://doi.org/10.1115/PVP2011-57814

[3] Herrera, I., Su, H., Kaczmarczyk, S. "Influence of the load occupancy ratio on the dynamic response of an elevator car system." Applied Mechanics and Materials. 706, pp. 128-136. 2015. https://doi.org/10.4028/www.scientific.net/AMM.706.128

[4] Xu, Y., Qian, Y.,Chen, J. J., Song, G.-B. "Stochastic dynamic characteristics of FGM beams with random material properties." Composite Structures. 133, pp. 585-594. 2015.

https://doi.org/10.1016/j.compstruct.2015.07.057

[5] Kaminski, M., Solecka, M. "Optimization of the truss-type structures using the generalized perturbation-based Stochastic Finite Element Method." Finite Elements in Analysis and Design. 63, pp. 69-79. 2013. https://doi.org/10.1016/j.finel.2012.08.002

[6] Lasota, R., Stocki, R., Tauzowski, P., Szolc, T. "Polynomial chaos expansion method in estimating probability distribution of rotor-shaft dynamic responses." Bulletin of the Polish Academy of Science-Technical Sciences. 63(2), pp. 413-422. 2015.

https://doi.org/10.1515/bpasts-2015-0047 
[7] Noguchi, N., Arakawa, A., Miyata, K., Yoshimura, T., Shin, S. "Study on active vibration control for high-speed elevators." Journal of System Design and Dynamics. 5(1), pp. 164-179. 2011.

https://doi.org/10.1299/jsdd.5.164

[8] Vladić, J., Jovanović, M., Đokić, R., Kljajin, M., Karakašić, M. "Theoretical and experimental analysis of mine elevator dynamic characteristics." Tehnicki Vjesnik-Technical Gazette. 22(4), pp. 1011-1020. 2015. https://doi.org/10.17559/TV-20150107175453

[9] Kaminski, M., Ossowski, R. L. "Prediction of the effective parameters of nanofluids using the generalied stochastic perturbation method." Physical A-statistical Mechanics and Its Applications." 93(1), pp. 10-22. 2010. https://doi.org/10.1016/j.physa.2013.09.015

[10] Kaminski, M. "Generalized stochastic perturbation technique in engineering computations." Mathematical and Computer Modelling. 51(3/4), pp. 272-285. 2010.

https://doi.org/10.1016/j.mcm.2009.08.014

[11] Kaminski, M. M., Szafran, J. "Random eigenvibrations of elastic structures by the response function method and the generalized stochastic perturbation technique." Archives of Civil and Mechanical Engineering. 9(4), pp. 5-32. 2009.

https://doi.org/10.1016/S1644-9665(12)60066-1

[12] Wu, F., Zhong, W. X. "A hybrid approach for the time domain analysis of linear stochastic structures." Computer Methods in Applied Mechanics and Engineering. 265, pp. 71-82. 2013.

https://doi.org/10.1016/j.cma.2013.06.006

[13] Zhao, B., Wang, Y.-Q., Chen, Z.-H., Shi, Y.-J., Jiang, Y., Wang, Y.-H. "Research on the random seismic response analysis for multi-and largespan structures to multi-support excitations." Earthquake Engineering and Engineering Vibration. 14(3), pp. 527-538. 2015.

https://doi.org/10.1007/s11803-015-0042-1
[14] Wu, Q., Li, D. P. "Analysis on pseudo excitation of random vibration for structure of time flight counter." Chinese Journal of Mechanical Engineering. 28(2), pp. 325-330. 2015. https://doi.org/10.3901/CJME.2014.1029.160

[15] Li, H. T., Wang, Q. B., Zong, Z., Sun, L., Liang, H. "Stochastic hydroelastic analysis of a very large floating structure using pseudo-excitation method." Applied Ocean Research. 48, pp. 202-213. 2014. https://doi.org/10.1016/j.apor.2014.08.003

[16] Liu, Y., Chen, L. Y., Yi, H. "Equivalent stochastic linearization for nonlinear uncertain structure under stationary Gaussian stochastic excitation." Journal of Shanghai Jiaotong University (Science). 19(1), pp. 123-128. 2014. https://doi.org/10.1007/s12204-014-1480-Z

[17] Wang, Y. F., Wang, S. J., Huang, L. H. "Random vibration analysis for impellers of centrifugal compressors through the pseudo-excitation method." International Journal of Computational Methods. 12(4), pp. 1-5. 2015. https://doi.org/10.1142/S0219876215400022

[18] Haciefendioglu, K., Basaga, H. B., Bayraktar, A., Ates, S. "Nonlinear analysis of rock-fill dams to non-stationary excitation by the stochastic Wilson-theta method." Applied Mathematics and Computation. 194(2), pp. 333-345. 2007. https://doi.org/10.1016/j.amc.2007.04.053

[19] Ozkul, T. A. "A finite element formulation for dynamic analysis of shells of general shape by using the Wilson- $\theta$ method." Thin-Walled Structures. 42(4), pp. 497-513. 2004.

https://doi.org/10.1016/j.tws.2003.12.008 